\title{
Red Eye of the Sun. The Art of the Papuan Gulf de Michael HAMSON
}

\section{Gilles Bounoure}

\section{OpenEdition}

Journals

Édition électronique

URL : http://journals.openedition.org/jso/6447

DOI : 10.4000/jso.6447

ISSN : $1760-7256$

Éditeur

Société des océanistes

\section{Édition imprimée}

Date de publication : 15 décembre 2011

Pagination : 429-430

ISBN : 978-2-85430-031-4

ISSN : 0300-953x

\section{Référence électronique}

Gilles Bounoure, "Red Eye of the Sun. The Art of the Papuan Gulf de Michael hamson », Journal de la Société des Océanistes [En ligne], 133 | 2e semestre 2011, mis en ligne le 31 décembre 2011, consulté le 24 septembre 2020. URL : http://journals.openedition.org/jso/6447 ; DOI : https://doi.org/10.4000/ jso.6447

Ce document a été généré automatiquement le 24 septembre 2020.

(c) Tous droits réservés 


\title{
Red Eye of the Sun. The Art of the Papuan Gulf de Michael HAMSON
}

\author{
Gilles Bounoure
}

\section{RÉFÉRENCE}

HAMsON Michael, 2010. Red Eye of the Sun. The Art of the Papuan Gulf, with essays by

Richard Aldridge, Crispin Howarth and Virginia-Lee Webb, Palos Verdes, M. Hamson

Oceanic Art, 192 pages, carte, bibliogr., nombreuses ill. noir et blanc et couleur.

1 Dû à un galeriste déjà cité dans cette rubrique (voir JSo 129), le présent ouvrage a bénéficié du concours de deux conservateurs, V.-L. Webb (« Framing Experiences : Early Photographs of the Papuan Golf», pp.12-19), qui poursuit ses analyses de photographies anciennes parues dans Coaxing the Spirits to Dance (2006, «In Situ: Photographs of Art in the Papuan Gulf» pp.52-79; voir jso 124), et C. Howarth («George Craig: Hunter and Collector», pp. 20-23), qui résume le parcours d'un chasseur de crocodiles australien devenu collecteur d'objets ethnographiques à la faveur de ses expéditions. Dans des sociétés anglo-saxonnes qui ne connaissent pas de frontière stricte entre les collections publiques et le marché de l'art, ces contributions n'ont rien d'étonnant. Elles rappellent aussi que chez les ethnologues et les gens de musée, le débat est loin d'être clos entre ceux qui rejettent au nom de solides considérations morales les publications à caractère commercial, catalogues de maisons de vente ou brochures de galeristes, et ceux qui pensent que toute information sérieuse est bonne à prendre, d'où qu'elle vienne. D'autres estiment aussi que le purisme n'est plus de mise quand tant d'institutions ou d'expositions en sont à dépendre du mécénat d'entreprise.

2 Si ce volume vise, sur le plan commercial, à établir la réputation des objets présentés (aucun prix n'est évidemment mentionné) et de celui qui les propose, il prétend aussi à quelque utilité sur le plan des connaissances, par son caractère monographique comme par son ambition de rassembler et de décrire des spécimens rarement étudiés. Les 
pièces reproduites ( 80 planches en couleur, avec leur description en regard) ne proviennent pas des collectes du galeriste, qui reconnaît n'avoir qu'une très mince expérience du golfe Papou (p. 7). Elles ont été recueillies pour la plupart dans les dernières années du mandat australien, il y a un bon demi-siècle, et certaines proviennent même des premiers missionnaires et coureurs de brousse qui alimentaient des marchands comme Webster, au début $\mathrm{du} \mathrm{xx}^{\mathrm{e}}$ siècle, toutes époques où il n'était guère question de déontologie de la collecte. Un petit tiers d'entre elles viennent de Richard Aldridge, qui se les est procurées sur place ou les a achetées à des collecteurs principalement chasseurs de crocodiles, tels George Craig (un dixième environ de l'ensemble) et Dick Randolph. Nombre d'autres n'ont apparemment pas d'histoire connue, et M. Hamson a dû se référer aux exemplaires publiés dans la littérature ethnographique pour en préciser l'origine.

3 Sans prétendre rivaliser avec Coaxing the Spirits to Dance, le dernier ouvrage en date sur les arts du golfe Papou, ce volume le complète à la fois géographiquement et typologiquement. Les objets décrits viennent pour plus de la moitié de l'est du golfe (Elema), mais les cultures sises plus à l'ouest sont également représentées par des pièces significatives, delta du Purari (3), Era River et Urama (8), Kerewa (5), Turama (2), Gogodala (3), Bamu (6), et même Kiwai (6), culture que n'illustrait pas l'ouvrage précité. Sont d'abord reproduites une douzaine de planches sculptées en champlevé (gope, kaiaimunu, hohao, kwoi, bioma, selon les cultures) auxquelles M. Hamson consacre un développement bien documenté. Leur succèdent deux suspensoirs à crânes (agiba, tutuapu), huit sculptures d'ancêtres ou d'esprits d'un type particulièrement rare, quatre sculptures zoomorphes, d'autres objets sculptés (cannes, têtes ornant les masques Gogodala) et une belle trentaine de noix de coco gravées à usage magique (marupai) Elema, dont un texte de R. Aldridge résume à peu près tout ce que l'on sait.

4 La suite du volume présente des objets peu fréquents dans la littérature, en raison de leur rareté (ainsi d'un «canot» d'initiation Gogodala) ou du peu d'intérêt traditionnellement marqué à la " petite ethnographie », massues et flèches, battoirs à tapa, cuillers, trompes d'appel et autres instruments de musique, spatules à chaux ou éléments de parure. À leur propos M. Hamson est souvent fondé à signaler les silences de la documentation publiée et à vouloir y remédier. Ainsi d'une gourde à chaux pour le bétel (pp.138-139) dont le décor pyrogravé en forme d'ombilic lui semble emblématique de la figuration Elema, et qu'il présente « as a small attempt to alleviate this problem ». Et s'il s'avère que Landtman a évoqué ce type d'objet (1933, p. 62 et pl. Xxiv, ouvrage que cite M. Hamson en bibliographie ; voir aussi 1927 p. 39 et fig. 40, ouvrage qu'il ne cite pas), et Wirz également dans un petit développement sur l'usage du bétel et ses accessoires (1934, p.38 et Taf. III, non cité par M. Hamson), il faut convenir que leurs descriptions trop brèves et allusives n'en rendent pas compte aussi bien que la photographie plus grande que nature et la notice que lui consacre ce volume, certes à but marchand, mais, ici comme sur d'autres sujets, réellement utile à la connaissance. 


\section{BIBLIOGRAPHIE}

LANDTMAN Gunnar, 1927. The Kiwai Papuans of British New Guinea. A Nature-born Instance of Rousseau's Ideal Community, London, Macmillan.

-, 1933. Ethnographical Collection from the Kiwai District of British New Guinea in the National Museum of Finland. A Descriptive Survey of the Material Culture of the Kiwai People, Helsingfors, Commission of the Antell Collection.

WELSCH Robert L. (ed.), 2006. Coaxing the Spirits to Dance. Art and Society in the Papuan Gulf of New Guinea, Hanover-New York, Hood Museum of Art-Metropolitan Museum of Art.

WIRz Paul, 1934. Beiträge zur Ethnographie des Papua-Golfes, Britisch-Neuguinea, Abhandlungen und Berichte der Museen für Tierkunde und Völkerkunde zu Dresden Band XIX, Leipzig, Teubner. 